\title{
Short stature, painful, curved lower limbs and multiple fractures
}

\author{
Haisong Chen • Yan Han • Xiaofei Li • Xuejun Liu • \\ Weihua Feng • Wenjian Xu
}

Published online: 24 June 2012

(C) ISS 2012

\section{History}

A 23-year old man presented with multiple recurrent fractures of the long bones with pain, bowing, short stature, and difficulty walking since childhood. He was a university graduate student and was well except for the skeletal abnormalities (Figs. 1, 2, 3, 4).

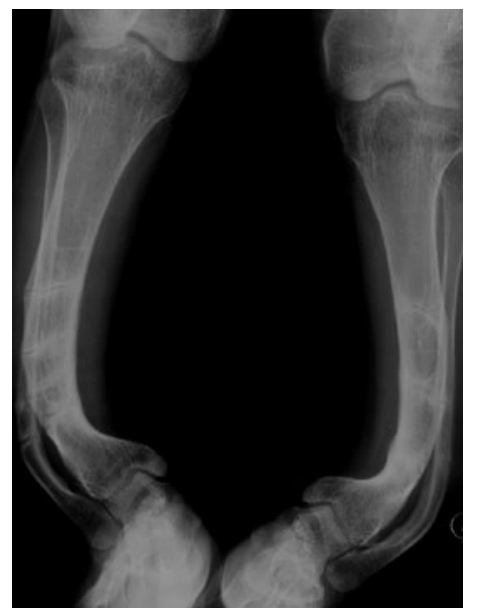

Fig. 1 Anterior-Posterior (AP) radiograph of bilateral tibiae and fibulas

The diagnosis can be found at doi:10.1007/s00256-012-1457-7.

H. Chen $\cdot$ X. Li $\cdot$ X. Liu $\cdot$ W. Feng $\cdot$ W. Xu $(\bowtie)$

Department of Radiology, the Affiliated Hospital of Medical

College Qingdao University,

Qingdao, China 266003

e-mail: 1021540101@qq.com

H. Chen

e-mail: chs368@sina.com

X. Li

e-mail: xiaofeili@sina.cn

X. Liu

e-mail: greenmark168@hotmail.com

W. Feng

e-mail: edward200811@163.com

Y. Han

Department of Scientific Research,

the Affiliated Hospital of Medical College Qingdao University,

Qingdao, China 266003

e-mail: idreaming_true@sohu.com 


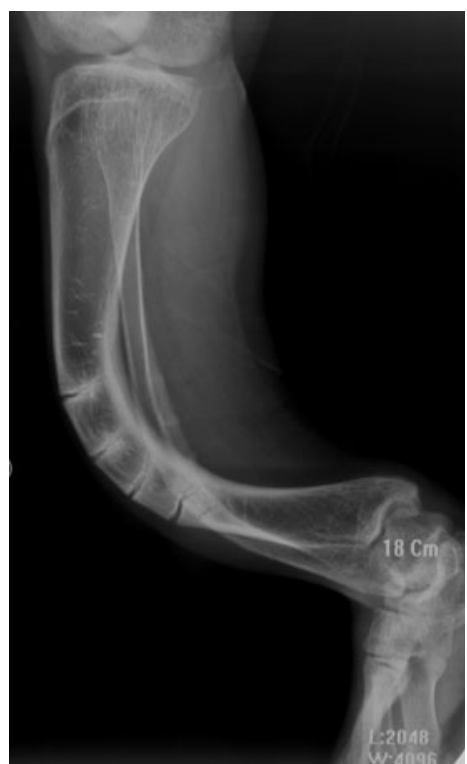

Fig. 2 Lateral radiograph of right tibia

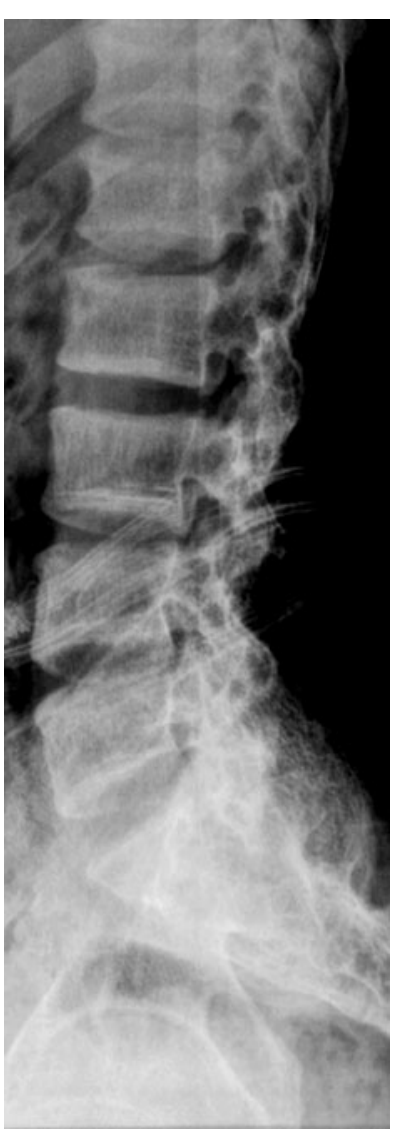

Fig. 4 Lateral radiograph of lumbar vertebrae

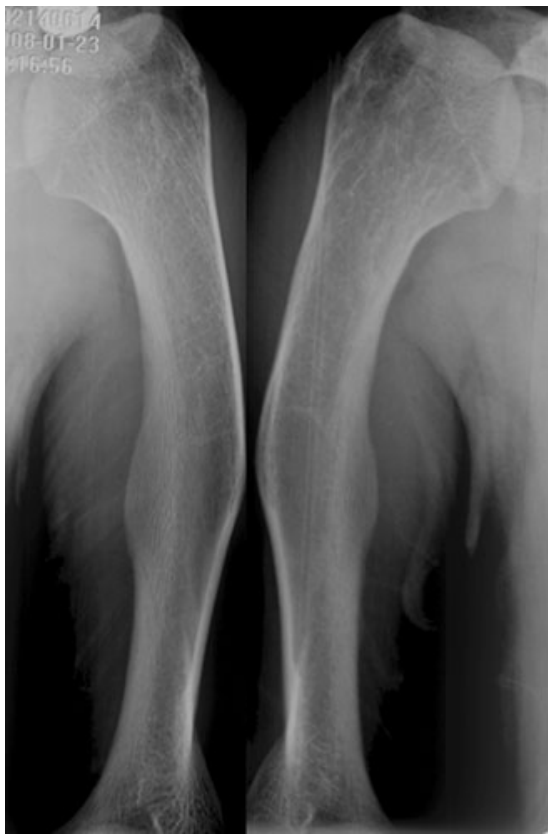

Fig. 3 Anterior-Posterior (AP) radiograph of bilateral humeri 